\title{
The Physical Quality of Milled Rice as Affected by Moisture Content and Relative Humidity during Delayed Rough Rice Drying
}

\author{
Tamrin $^{1 *}$, Filli Pratama², Bagus Septian ${ }^{1}$
}

${ }^{I}$ Study Program of Agricultural Engineering, Faculty of Agriculture, Universitas Sriwijaya, Inderalaya, 30662, South Sumatera, Indonesia ${ }^{2}$ Study Program of Agricultural Product Technology, Faculty of Agriculture, Universitas Sriwijaya, Inderalaya, 30662, South Sumatera, Indonesia

\section{A R T I C LE IN F O}

\section{Research Article}

Received 26 March 2017

Accepted 25 May 2017

Keywords:

Rough rice

Delayed drying

Moisture

Humidity

Physical quality

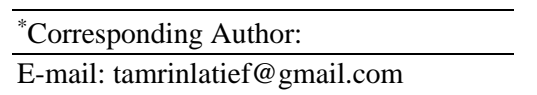
\begin{abstract}
A B S T R A C T
Delayed rough rice drying was often found in tidal low land in Indonesia due to rice harvesting used to be in rainy season. Moisture re-absorption of rough rice during delayed drying caused fissures and breakage after rice milling. This experimental works condition the rough rice in some different moisture content and relative humidity during delayed drying. This aim of this study was to develop an alternative condition of delayed rough rice for drying so as not to significantly affect the physical quality of milled rice. The experiment was arranged as a factorial-randomized block design. Each treatment was repeated three times. Rough rice of IR42 variety was selected at three level of moisture content $(24.89 \%, 18 \%$ and $22 \%)$, and was stored in a closed vessel at the relative humidity of $76 \%$ and $86 \%$. The percentage of whole grain, head rice, large broken grain, and small broken grain were daily assessed until 7 days of delayed drying duration. The results showed that the moisture content and relative humidity had a significant effect on all parameters on each day of delayed rough rice drying duration. Rough rice would be better delayed for drying at the conditions for moisture content of $22 \%$ and relative humidity of $86 \%$.
\end{abstract}

DOI: https://doi.org/10.24925/turjaf.v5i11.1261-1263.1244

\section{Introduction}

Land for rice production in Indonesia is decreasing due to loss of agricultural land for urbanization, industries and infrastructures; therefore the marginal land such as tidal low land was used for rice production. The tidal low land gives beneficial for rice growth for its water supply. Rice harvesting in tidal low land used to be in dry season; however, due to global climate change, rice harvesting is often in rainy season. It is unavoidable that there would be delayed rough rice drying due to lack of sunlight in rainy season as well as limited amount of rice mills.

During delayed drying, rough rice was stacked without an appropriate cover; therefore it would absorb moisture from surrounding environment and increase its moisture content. Rice farmers used to delay rough rice drying for two to seven days. The moisture content of the rough rice fluctuates during delayed drying due to differences in temperature and humidity in day and night. This condition would have an effect on the physical and physicochemical properties of milled rice.

There were some studies on the effect of environmental condition on rice quality. Ondier et al. (2010) determined the rice quality of rice as affected by low-temperature and low-relative humidity drying of rough rice. Luangmalawat et al. (2008) investigated the effect of temperature on drying characteristics and quality of cooked rice. Allameh and Alizadeh (2013) evaluated the rice losses during delayed rough rice drying in Iran. Wiset et al. (2005) assessed the physicochemical properties of various cultivars of rice as affected by hightemperature during rough rice drying. Unfortunately those studied did not evaluate the physical quality of milled rice during delayed rough rice for drying. This finding would be the basis for determining the best condition of delayed rough rice for drying, particularly in tidal low land rice field in Indonesia.

\section{Materials and Methods}

\section{Rough Rice Variety}

The rough rice variety of IR42 was harvested from Mulya Sari village, Tanjung Lago sub-district, Banyuasin District, south Sumatera, Indonesia.

\section{Rough Rice Preparation}

Rough rice samples were grouped in three levels of moisture content (MC), they were freshly harvested rough rice (designated as $\mathrm{A} 1$, at MC $24.89 \%$ wet basis (wb)), rough rice was conditioned at MC $18 \%$ wb (A2) and 22\% 
wb (A3) wet basis. Rough rice sample as amount of $600 \mathrm{~g}$ was placed in a closed vessel that had been conditioned to a certain relative humidity $(\mathrm{RH})$, namely $\mathrm{RH} 76 \%$ (designated as B1) and $86 \%$ (designated as B2). The $\mathrm{RH}$ of $76 \%$ was adjusted by using saturated salt solution of potassium chloride $(\mathrm{KCl})$ and the $\mathrm{RH}$ of $86 \%$ was adjusted by using sodium chloride $(\mathrm{NaCl})$ (Greenspan, 1977).

Rough rice in the closed vessel was left for 4 hours to achieve the equilibrium RH. Rough rice in the closed vessel was periodically taken out in every 24 hours as amount of $50 \mathrm{~g}$ to be dried to achieve $14 \%$ of MC. The rough rice sample was then milled with mini rice mill to remove all bran layers (Satake Rice Machine, type THU, class 35A, Satake Engineering Co. Ltd., Japan) at degree of milling of $15 \%$ (all bran layers removed).

The obtained milled rice was analyzed for the percentage of whole grains (WG), head rice (HR), large broken grain (LBG) and small broken grains (SBG). WG was defined as no broken kernel occurred in milled rice kernel; HR is defined as milled rice grain with the length of $>75 \%$ of the original length of WG; $\mathrm{LBG}$ is in between $25 \%$ and $75 \%$ of the original length of $\mathrm{WG}$, whereas SBG was less than $25 \%$ of the original length of WG (SNI 01-6128:2008).

\section{Statistical Analysis}

The experiment was designed as a FactorialRandomized Block Design. The first factor (A) was the $\mathrm{MC}$ of rough rice, and the second factor (B) was the storage $\mathrm{RH}$ in a closed vessel. Each treatment was repeated three times. Statistical analysis was carried by ANOVA (analysis of variance), and the significant effect of the treatment $(p<0.05)$ was further analyzed by Tukey's Honestly Significant Difference (HSD) Test.

\section{Results and Discussion}

Percentages of WG, HR, LBG, and SBG during delayed rough rice drying (daily observed for 7 days) were presented in Fig. 1 to 4. Analysis of variance shows that rough rice $\mathrm{MC}$, and storage $\mathrm{RH}$ had significant effect on WG, HR, LB and SBG of milled rice in each daily observation. The interaction between rough rice $\mathrm{MC}$, and storage RH had significant effect on HR on day 1, 2 and 3 (Table 1).

Table 1 Tukey's HSD test of HR on day 1,2 and 3

\begin{tabular}{l|ccc}
\hline Treatment & Day 1 & Day 2 & Day 3 \\
\hline A1B2 & $19.30^{\mathrm{a}}$ & $19.62^{\mathrm{a}}$ & $19.86^{\mathrm{a}}$ \\
$\mathrm{A} 2 \mathrm{~B} 2$ & $26.68^{\mathrm{b}}$ & $28.58^{\mathrm{b}}$ & $27.86^{\mathrm{b}}$ \\
$\mathrm{A} 1 \mathrm{~B} 1$ & $27.12^{\mathrm{b}}$ & $27.66^{\mathrm{b}}$ & $28.68^{\mathrm{b}}$ \\
$\mathrm{A} 2 \mathrm{~B} 1$ & $32.94^{\mathrm{c}}$ & $33.72^{\mathrm{c}}$ & $34.92^{\mathrm{c}}$ \\
$\mathrm{A} 3 \mathrm{~B} 2$ & $36.40^{\mathrm{c}}$ & $37.46^{\mathrm{c}}$ & $38.62^{\mathrm{c}}$ \\
$\mathrm{A} 3 \mathrm{~B} 1$ & $38.30^{\mathrm{c}}$ & $39.51^{\mathrm{c}}$ & $39.80^{\mathrm{c}}$ \\
\hline HSD 0.05 & 4.53 & 5.10 & 4.26 \\
\hline Means with different superscript letters are significantly different \\
(P<0.05)
\end{tabular}

Figure 4 Small broken grains $(\%)$ during delayed rough
rice drying (A1, A2, A3 = rough rice at MC 24.89\%, 18\%, 22\%, respectively. $\mathrm{B} 1=\mathrm{RH} 76 \%, \mathrm{~B} 2=\mathrm{RH} 86 \%)$ 
The delayed rough drying at the MC of $22 \%$ resulted in higher percentage of WG and HR in both $\mathrm{RH}$ of $76 \%$ and $86 \%$. The RH of $76 \%$ and $86 \%$ are considered as high humidity which are common in tropical countries, particularly in tidal low land. There would be small amount of moisture transfer in high MC of rough rice; therefore rice would be resistant to form fissures during rice drying. Fissures in rice would result in breakage during rice milling. As stated by Lan and Kunze (1996), fissures were formed due to internal stresses in the rice grains during moisture re-adsorption from the surrounding environment.

WG and HR are two important indices in judging the quality milled rice in Indonesia; however, in some countries, HR is frequently used as important quality in assessing milled rice quality. There were some physicochemical changes in endosperm of rough rice. The kernel would absorb moisture from the surrounding environment; the lower $\mathrm{MC}$ of rough rice, more absorption would be in rough rice. The increase of $\mathrm{MC}$ in rice would result in volumetric changes in rice kernel. Due to rough rice is protected by rice husk, the absorption mostly occurs on the surface layer of its endosperm. Internal fissures might develop during rough rice drying and resulted in rice breakage (Siebenmorgen et al., 2005). Moisture increase in rice resulted in a different changes between the inner and outer section of rice kernel; and the internal rice kernel might be stressed due to a tight and compact husk. If there was a great different between the moisture in inner and outer kernel, fissures might develop in the rice grain (Iguaz et al., 2006). The breakage of milled rice would increase due to the mechanical stress during rice milling. As shown in Fig. 1 to 4 that the breakage kernels distribution is increasing along with the delayed drying duration for the LBG and SBG; on the other hand, the WG and HR are decreasing. The significant finding in this study was the delayed rough rice drying would be better in the $\mathrm{MC}$ of $22 \%$ and $\mathrm{RH}$ of $86 \%$ (high humidity).

\section{Conclusion}

Most of rough rice in low land of Indonesia was not dried immediately after harvested due to lack of sunlight in rainy season. In such condition, the rough rice was better delayed for drying at a higher MC (22\% wb) (slightly higher than safe MC for rough rice storage) and high $\mathrm{RH}(86 \%)$ for increasing the percentage of $\mathrm{WG}$ and $\mathrm{HR}$. The best delayed rough rice drying duration in such conditions should not exceed 3 days.

\section{Acknowledgment}

Authors should thank to Universitas Sriwijaya for the financial support for conducting this study

\section{References}

Allameh A, Alizadeh MR. 2013. Evaluating rice losses in delayed rough rice drying. Intl J Agron Plant Prod 4(4): 799-804.

Greenspan L. 1977. Humidity fixed points of binary saturated aqueous solutions. Journal of Research of the National Bureau of Standards-A. Physics and Chemistry 81A(1):89-96.

Iguaz A, Rodriguez M, Virseda P. 2006. Influence of handling and processing of rough rice on fissures and head rice yields. J Food Eng 77: 803-809.

Luangmalawat P, Prachayawarakorn S, Nathakaranakule A, Soponronnarit S. 2008. Effect of temperature on drying characteristics and quality of cooked rice. LWT 41: 716-723.

National Standard Body. 2008. [Rice]. National Standard Body, Standard National Indonesia (SNI) 01-6128:2008, (In Indonesian).

Ondier GO, Siebenmorgen TJ, Mauromoustakos A. 2010. Lowtemperature, low-relative humidity drying of rough rice. J Food Eng 100: 545-550.

Siebernmorgen TJ, Bautista RC, Qin G. 2005. Influence of drying on rice fissure formation rates and mechanical strength distributions. B.R. Wells Rice Research Studies, 396-403.

Wiset L, Srzednicki G, Wooton, M. 2005. Effects of hightemperature drying on physicochemical properties of various cultivars of rice. Drying Technol 23: 2227-2237. 